\title{
Student satisfaction with videoconferencing teaching quality during the COVID-19 pandemic
}

Tarah H. Fatani(i)

\begin{abstract}
Background: The coronavirus disease 2019 pandemic prompted the pediatric department at King Abdulaziz University to continue students' educational activities by offering courses online that utilized web video conferencing (WVC). Given the uncertainties of WVC educational quality and the challenge of shifting to an online environment, this study aimed to evaluate student satisfaction with the teaching quality of case-based discussion (CBD) sessions conducted through WVC.

Methods: One hundred sixty-two undergraduate medical students in pediatrics completed the reduced Students' Evaluation of Educational Quality (SEEQ) survey with a five-point Likert scale over 5 weeks. The WVC CBD sessions were facilitated by 50 faculty members.

Results: $82 \%$ of respondents were highly satisfied with the WVC CBD session's teaching quality. The majority agreed that the sessions were intellectually challenging, that the instructors were dynamic, and encouraged students to participate. No statistically significant correlation was found between student satisfaction and technical issues $(r=0.037, p=0.003)$.

Conclusions: WVC teaching had an overall positive outcome on student satisfaction, and teaching quality relied on teaching, cognitive, and social presence rather than technology. However, technology remains an important platform that supports teachers' educational activities. Thus, implementing a blended pediatric course to augment future course delivery is optimal.
\end{abstract}

Keywords: Student satisfaction, Student evaluation of education quality, Community of inquiry, Videoconferencing, COVID-19

\section{Background}

The coronavirus disease 2019 (COVID-19) pandemic has changed medical education; the United Nations Educational, Scientific, and Cultural Organization (UNESCO) announced that 1.2 billion students across the planet have been affected by school and university closures due to the pandemic [1]. Saudi Arabia is one of the many countries that made the unprecedented decision to close schools

Correspondence: hfatani@kau.edu.sa

Department of Pediatrics, Pediatric Endocrinology, King Abdulaziz University, Jeddah 21589, Saudi Arabia

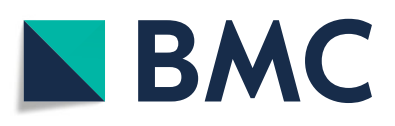

and universities to contain the spread of the deadly virus as social distancing has been the most effective preventative strategy for COVID-19 pending development of a vaccine, treatment, or both [2].

At King Abdulaziz University, this closure dramatically interrupted medical students' educational activities and clinical training, prompting the institution to move the course of study online and contemplate new approaches to distance education. Faculty members in the pediatric department shifted from in-person to distance education to facilitate students' education. However, for many in

(c) The Author(s). 2020 Open Access This article is licensed under a Creative Commons Attribution 4.0 International License, which permits use, sharing, adaptation, distribution and reproduction in any medium or format, as long as you give appropriate credit to the original author(s) and the source, provide a link to the Creative Commons licence, and indicate if changes were made. The images or other third party material in this article are included in the article's Creative Commons licence, unless indicated otherwise in a credit line to the material. If material is not included in the article's Creative Commons licence and your intended use is not permitted by statutory regulation or exceeds the permitted use, you will need to obtain permission directly from the copyright holder. To view a copy of this licence, visit http://creativecommons.org/licenses/by/4.0/. The Creative Commons Public Domain Dedication waiver (http://creativecommons.org/publicdomain/zero/1.0/) applies to the data made available in this article, unless otherwise stated in a credit line to the data. 
the department, web video conferencing (WVC) technologies and online education were new and challenging.

The educators had to meet four major online education challenges: demonstrating pedagogical skills in an online classroom, addressing their managerial role, establishing relationships with students, and providing technical support $[3,4]$. Despite the challenges, the instructors had to effectively facilitate case-based discussion (CBD) via WVC while maintaining a high-quality, authentic learning experience with high student satisfaction rates.

\section{Distance education and student satisfaction}

Distance education is defined as learning activities within formal, informal, or non-formal domains that are facilitated by information and communication technologies to lessen distance, both physically and psychologically, and to increase interactivity and communication among learners, learning sources, and facilitators [5]. Distance education has become the basic global mode of course delivery, and the quality of this delivery is essential.

The five elements in the Sloan quality framework for effective online education are student satisfaction, learning effectiveness, faculty satisfaction, student access, and institutional cost-effectiveness [6]. Furthermore, the root causes of online learning success are motive and leadership, focus on the program, faculty support, students (satisfaction, services, outcome), and growth in student enrolment [7]. Thus, the quality of online learning is highly influenced by teaching rather than technology [7].

A systematic review of randomized controlled trials concluded that digital problem-based learning (DPBL) was potentially more effective in improving knowledge and skills than traditional problem-based learning (PBL) due to greater student interaction and engagement in DPBL [8]. However, the review found mixed data concerning student satisfaction outcomes [8]. Various studies on student satisfaction with online learning have identified the following factors: instructor interaction, communication, active learning, students' ability to initiate and control their actions in the learning environment, efficient assessment of academic progress, technology, and the learning environment $[9,10]$.

\section{Video conferencing and student satisfaction}

WVC is a synchronous model for interactive voice, video, and data transfer between two or more groups. It enables real-time, two-way video and audio communication as well as content sharing and messaging between instructors and students [11, 12]. Additionally, it allows immediate feedback and supports collaborative learning among students $[11,12]$. WVC allows learners and instructors to participate in web-based discussions that are not bound to certain hardware or software, utilizing services such as Zoom, Skype for Business, and GoToMeeting [12]. As technology advances, WVC has become one of the most common tools used for synchronous online teaching $[13,14]$. It promotes dynamic collaborative efforts, although it does face challenges with technical issues [12].

The findings on student satisfaction with WVC have been mixed. Dawson showed that synchronous communication increases the sense of classroom community and, therefore, student satisfaction [15]. Additionally, in a study by Dogget, over $90 \%$ of students responded favourably to the instructor's use of WVC and his/her encouragement to ask questions; however, $80 \%$ stated that they would have been more comfortable in a conventional classroom setting, and 57\% agreed that WVC technology was a barrier to interacting with the instructor [16]. Smith et al. [17] demonstrated that WVC was an effective method for satisfactorily teaching surgical tutorials to medical students. In contrast, Giesbers et al. [18] compared the learning experience of students using discussion forums (DF) versus students using both DF and WVC (which is expected to increase social presence) and found that WVC was not associated with enhanced student learning during their four-year experience with WVC. The only exceptions were the clarification of the module's goals and tasks [19].

\section{Video conferencing and case-based discussions}

$\mathrm{CBD}$ is an interactive, student-centered learning approach closely related to PBL. CBD utilizes real-life scenarios that the students would have faced during the clinical phase of their pediatric rotation [18]. It aims to enable students to learn from patients' cases, to enhance their problem-solving skills, and to encourage them to think analytically about the patient's case from various angles. CBD has several advantages. It promotes active, self-directed, life-long learning; integrates basic medical knowledge with clinical cases; emphasizes clinical reasoning when approaching a case; and develops student communication skills [18]. Information about the case from history, physical examination, and investigation is given in a step-wise manner to allow students to analyze the information and generate differential diagnoses. The students then strive to reach the most likely diagnosis and appropriate management.

WVC is an optimal choice to facilitate CBD sessions as it will increase social presence which help the acquisition of information, focus on learner-centered opportunities, engage students and allow small group interactions, allow instructors to observe and assess students working in real-life learning experience, develop positive communication skills, demonstrate leadership, and shared responsibility as they analytically think about how to approach a Pediatric case. However, problems using 
WVC for conducting the sessions are destined to occur such as experiencing technology issues, confidence navigating the platform by both instructor and students, ensuring student engagement, and delivering creative and effective educational practices in an online learning environment [20].

\section{Community of inquiry framework}

The community of inquiry (COI) framework constitutes three critical elements of online education-cognitive, teaching, and social presence-as well as the internal dynamic relationships among them [21]. Presence is defined as a state of alert awareness, receptivity, and connectedness to the mental, emotional, and physical workings of the individual and the group in the context of their learning environments, as well as the ability to respond with a considered and compassionate best next step [22]. Cognitive presence is the extent to which leaners are able to construct and confirm meaning through sustained reflection and discourse. It is implemented through the Practical Inquiry model consisting of four phases: triggering event, exploration, integration and resolution [21]. Teaching presence is the design, facilitation, and direction of cognitive and social processes, while social presence is the ability of the learners to identify with the community, communicate purposefully and develop inter-personal relationships by way of projecting their individual personalities [21]. These three interdependent elements are essential for delivering a successful asynchronous (i.e. not simultaneous) online course and creating an effective educational experience [21]. The SEEQ questionnaire shares the same concepts as the COI framework (cognitive, teaching, and social presence); questions exploring student learning reflect cognitive presence, questions exploring enthusiasm and organization reflect teaching presence, and questions on group interaction and individual rapport reflect teaching and social presence combined.

The relevance of the COI framework to synchronous (i.e., simultaneous interaction) online learning with WVC technology needs to be further verified. According to Moore, using interactive teleconference media offers the opportunity for dynamic inter-learner dialogue and student engagement, thereby enabling instructors to bridge the psychological and communication distance between instructors and learners and among learners. It also provides the opportunity to develop the cognitive skills of analysis and autonomy [23].

Given the novel exposure to distance education for both students and faculty members, this study aimed to evaluate student satisfaction with the teaching quality of case-based discussion (CBD) sessions conducted through WVC. Furthermore, students' ongoing feedback about their satisfaction with the teaching quality will substantially impact future curriculum planning and design as further online pediatric courses are implemented.

\section{Methods \\ Participants}

This study enrolled 162 fifth-year male Saudi undergraduate medical students who were in the pediatric rotation course at King Abdulaziz University for 12 weeks from March to May 2020. The students were divided into 14 groups with 10-12 students in each group. All students were between 21 and 25 years old. The students' attendance at each CBD was compulsory and monitored throughout the course.

\section{Pediatric course description}

The pediatric course at King Abdulaziz University used the online platform Blackboard Ultra before the COVID19 outbreak; this platform integrates course learning outcomes, student study guides, assignments, and assessments. Traditionally, the pediatric course is a 12-week rotation at the end of the academic year during which fifth-year medical students are exposed to clinical inpatient and outpatient environments and participate in face-to-face CBD and clinical sessions in a hospital. None of these educational activities was provided via distance education before the COVID-19 outbreak, and the CBD sessions were conducted by the students and facilitated by the teachers to enhance active learning. In order to prepare the faculty members for successful online course teaching, King Abdulaziz university provided faculty members with nonmandatory Blackboard development courses on online education and teaching, course delivery and navigation, and technical requirements.

The COVID-19 outbreak occurred 2 weeks through the rotation, and the university reduced the course to a duration of 9 weeks. This left 5 weeks to deliver the course online and 2 weeks to complete the assessment and final examinations.

To ensure that the remaining course objectives were met, 10 faculty members collaborated to identify the most crucial topics in the fifth-year undergraduate medical curriculum. They also decided whether the educational activity should be delivered asynchronously or synchronously. These faculty members identified 11 asynchronous lectures and 17 synchronous CBD to be delivered online over 5 weeks by 50 pediatric faculty members according to their area of interest or subspecialty.

\section{Video conferencing session administration}

For 5 weeks, each instructor facilitated 1 or 2 CBD sessions weekly to cover $17 \mathrm{CBD}$ topics. Each session was allocated a 2-h duration and involved a set of 1 or 2 groups of students (10-12 students per group). The 
WVC options were Blackboard Ultra and Zoom. Because Blackboard Ultra is the learning management system (LMS) platform used by the university for course delivery, it faced high pressure during this period since most university instructors were utilizing it. After piloting both platforms, the instructors reported easier navigation and fewer interruptions, connection dropouts, and audio-visual problems using Zoom.

Zoom is an innovative meeting company that unifies cloud WVC, simple web meetings, and group collaboration in one easy-to-use platform. It has been one of the most extensively used tools for facilitating ongoing synchronous educational activities during the COVID-19 pandemic $[24,25]$. Furthermore, it allows wireless screen and whiteboard sharing, has an interactive chat room, and is free for up to $40 \mathrm{~min}$. Thus, it is an optimal choice for facilitating synchronous teaching activities to provide an optimal learning experience with enhanced student and instructor engagement [26].

In preparation for the $\mathrm{CBD}$ sessions, instructors received the CBD learning outcomes and the list of students participating in the discussion. Additionally, a full orientation on using Zoom was provided for all academic pediatric faculty members through a half-day workshop. After the workshop, an e-mail link was sent to both students and faculty members with a demonstrative video recorded by one of the pediatric faculty members providing simple explanations on utilizing Zoom in Arabic.

\section{Students' evaluation of educational quality}

The reduced version of the Students' Evaluation of Educational Quality (SEEQ) was chosen as the survey tool to evaluate the teaching quality of the WVC CBD sessions. The SEEQ was developed by Marsh in 1987 to assess the level of student satisfaction with teacher effectiveness to improve teaching quality [27]. The reduced SEEQ has been internationally validated for research studies [28]. It has a robust quality, excellent reliability and internal consistency, and reasonable validity, and has the flexibility to fit individual teaching contexts. It is useful for rapidly acquiring data and minimizing the risks of item non-response, and it has been extensively utilized in many courses worldwide at both the graduate and undergraduate levels $[29,30]$. The SEEQ questionnaire examines nine characteristics of effective learning: learning, individual rapport, enthusiasm, examinations, organization, breadth, group interaction, assignments, and overall rating.

\section{Data collection}

Following an initial pilot questionnaire completed by one group of 10 students and reviewed by three pediatric faculty members, the questionnaire categories were tailored to be more relevant to the WVC CBD sessions. We eliminated 2 questions from the original reduced SEEQ questionnaire, one under the category of enthusiasm related to using humour, and the second under the category of individual rapport related to the instructor being friendly toward individual students. Moreover, we added 2 technology questions relevant to the use of WVC. The final questionnaire contained the following 21 items: 1 question on the assigned student group; 2 questions about the CBD session (topic, date, and time); 14 reduced SEEQ factors focusing on learning (Q4-Q7), enthusiasm (Q8-Q9), organization $(\mathrm{Q} 10-\mathrm{Q} 12)$, group interaction $(\mathrm{Q} 13-\mathrm{Q} 15)$, and individual rapport (Q16Q17); we added 2 questions relevant to WVC technology usage (faculty creativity and audio/visual technical issues); 1 question about student satisfaction with the CBD session quality; and 1 open-ended question that allowed students to comment on their experience. A 5point Likert scale ranging from 1 (strongly disagree) to 5 (strongly agree) was used.

After approval from the Research Ethics Committee at King Abdulaziz University Hospital, an attached invitation letter was sent via weblink explaining the purpose of the study and students were asked to complete the survey for one CBD on a weekly bases for 5 weeks duration, and to rate the degree to which they agreed or disagreed with each item on the survey. The SurveyMonkey was sent over the course of 5 weeks to all group leaders to be distributed among their fellow students. The students' participation was voluntary and anonymous, and they were able to withdraw at any time.

\section{Statistical analysis}

Data were collected using SurveyMonkey and then analyzed using Statistical Package for Social Science (SPSS) version 22.0 to determine the means and standard deviations of the questionnaire items. The analysis relied on having no group differences. The mean for each of the items was compared between the high-satisfaction group (HSG) and low-satisfaction group (LSG) with a 95\% confidence interval $(\mathrm{CI})$ using independent sample t-tests. A student was assigned to the HSG if the overall CBD satisfaction response rated as agree or strongly agree on the 5-point Likert scale or to the LSG if he rated the response as strongly disagree, disagree, or neutral. Pearson's correlation coefficient was used to assess the correlations between student satisfaction and technology usage.

\section{Results}

A total of 662 male student responses were received (an overall response rate of $82 \%$ ). Table 1 displays the descriptive analysis of the of reduced SEEQ responses by degree of overall Student Satisfaction. As shown, 
Table 1 Descriptive Statistics of Responses to the Reduced SEEQ by Degree of Overall Student Satisfaction

\begin{tabular}{|c|c|c|c|c|c|}
\hline SEEQ item & $\begin{array}{l}\text { Overall Mean } \\
\text { (SD), } N=662\end{array}$ & $\begin{array}{l}\text { HSG Mean } \\
\text { (SD), } N=543\end{array}$ & $\begin{array}{l}\text { LSG Mean } \\
\text { (SD), } N=119\end{array}$ & $\begin{array}{l}\mathrm{MD}(95 \% \\
\mathrm{Cl})\end{array}$ & $\begin{array}{l}p- \\
\text { Value }\end{array}$ \\
\hline \multicolumn{6}{|l|}{ *Learning } \\
\hline $\begin{array}{l}4 \text { I have found this CBD session intellectually challenging and } \\
\text { stimulating. }\end{array}$ & $4.08(0.863)$ & $4.30(0.629)$ & $3.08(1.062)$ & $\begin{array}{l}1.218 \\
(1.074- \\
1.362)\end{array}$ & $\begin{array}{l}< \\
0.001\end{array}$ \\
\hline 5 I have learned and understood the subject materials of this CBD. & $4.12(0.836)$ & $4.35(0.588)$ & $3.09(1.008)$ & $\begin{array}{l}1.257 \\
(1.122- \\
1.393)\end{array}$ & $\begin{array}{l}< \\
0.001\end{array}$ \\
\hline $\begin{array}{l}6 \text { My interest and motivation in learning have increased as a } \\
\text { consequence of this CBD session. }\end{array}$ & $4.04(0.934)$ & $4.29(0.684)$ & $2.89(1.056)$ & $\begin{array}{l}1.398 \\
(1.247- \\
1.550)\end{array}$ & $\begin{array}{l}< \\
0.001\end{array}$ \\
\hline 7 The faculty member covered the stated objectives for this CBD session. & $4.162(0.821)$ & $4.354(0.654)$ & $3.286(0.931)$ & $\begin{array}{l}1.067 \\
(0.926- \\
1.209)\end{array}$ & $\begin{array}{l}< \\
0.001\end{array}$ \\
\hline \multicolumn{6}{|l|}{ *Enthusiasm } \\
\hline $\begin{array}{l}8 \text { The faculty member was enthusiastic (excited) about teaching this CBD } \\
\text { session. }\end{array}$ & $4.17(0.852)$ & $4.38(0.620)$ & $3.18(1.057)$ & $\begin{array}{l}1.196 \\
(1.054- \\
1.339)\end{array}$ & $\begin{array}{l}< \\
0.001\end{array}$ \\
\hline $\begin{array}{l}9 \text { The faculty member was dynamic (style of presentation holds your } \\
\text { interest) and energetic during this CBD session. }\end{array}$ & $4.08(0.949)$ & $4.35(0.659)$ & $2.86(1.099)$ & $\begin{array}{l}1.493 \\
(1.342- \\
1.643)\end{array}$ & $\begin{array}{l}< \\
0.001\end{array}$ \\
\hline \multicolumn{6}{|l|}{ *Organization } \\
\hline 10 The faculty member's explanations were clear. & $4.20(0.851)$ & $4.43(0.603)$ & $3.15(1.022)$ & $\begin{array}{l}1.276 \\
(1.138- \\
1.414)\end{array}$ & $\begin{array}{l}< \\
0.001\end{array}$ \\
\hline 11 The CBD material was well prepared and carefully explained. & $4.10(0.908)$ & $4.35(0.624)$ & $2.97(1.119)$ & $\begin{array}{l}1.380 \\
(1.233- \\
1.526)\end{array}$ & $\begin{array}{l}< \\
0.001\end{array}$ \\
\hline 12 The faculty member gave a CBD session that facilitated taking notes. & $4.06(0.917)$ & $3.00(1.112)$ & $3.00(1.112)$ & $\begin{array}{l}1.289 \\
(1.136- \\
1.443)\end{array}$ & $\begin{array}{l}< \\
0.001\end{array}$ \\
\hline \multicolumn{6}{|l|}{ *Group interaction } \\
\hline 13 Students were encouraged to participate in this CBD session. & $4.23(0.781)$ & $4.40(0.586)$ & $3.47(1.064)$ & $\begin{array}{l}0.925 \\
(0.787- \\
1.064)\end{array}$ & $\begin{array}{l}< \\
0.001\end{array}$ \\
\hline 14 Students were invited to share their ideas and knowledge. & $4.19(0.829)$ & $4.37(0.617)$ & $3.34(1.108)$ & $\begin{array}{l}1.026 \\
(0.881- \\
1.171)\end{array}$ & $\begin{array}{l}< \\
0.001\end{array}$ \\
\hline $\begin{array}{l}15 \text { Students were encouraged to ask questions and were given } \\
\text { meaningful answers. }\end{array}$ & $4.18(0.819)$ & $4.35(0.642)$ & $3.43(1.078)$ & $\begin{array}{l}0.919 \\
(0.773- \\
1.066)\end{array}$ & $\begin{array}{l}< \\
0.001\end{array}$ \\
\hline \multicolumn{6}{|l|}{ *Individual rapport } \\
\hline $\begin{array}{l}16 \text { The faculty member made the students feel welcome in seeking } \\
\text { help/advice regarding learning challenges during COVID-19. }\end{array}$ & $4.04(0.944)$ & $4.26(0.749)$ & $3.06(1.107)$ & $\begin{array}{l}1.199 \\
(1.035- \\
1.363)\end{array}$ & $\begin{array}{l}< \\
0.001\end{array}$ \\
\hline 17 The faculty member had a genuine (sincere) interest in students. & $4.08(0.874)$ & $4.29(0.674)$ & $3.13(1.030)$ & $\begin{array}{l}1.167 \\
(1.018- \\
1.316)\end{array}$ & $\begin{array}{l}< \\
0.001\end{array}$ \\
\hline \multicolumn{6}{|l|}{ *Technology } \\
\hline $\begin{array}{l}18 \text { The faculty member was creative (used whiteboard, chat room, } \\
\text { videos, web materials, etc.). }\end{array}$ & $3.95(0.996)$ & $4.15(0.838)$ & $3.03(1.134)$ & $\begin{array}{l}1.121 \\
(0.942- \\
1.300)\end{array}$ & $\begin{array}{l}< \\
0.001\end{array}$ \\
\hline 19 During this CBD session, there were technical issues (audio/visual). & $2.82(1.355)$ & $2.85(1.389)$ & $2.67(1.180)$ & $\begin{array}{l}0.177 \\
(-0.092- \\
0.446)\end{array}$ & 0.198 \\
\hline
\end{tabular}


Table 1 Descriptive Statistics of Responses to the Reduced SEEQ by Degree of Overall Student Satisfaction (Continued)

\begin{tabular}{|c|c|c|c|c|c|}
\hline SEEQ item & $\begin{array}{l}\text { Overall Mean } \\
\text { (SD), } N=662\end{array}$ & $\begin{array}{l}\text { HSG Mean } \\
\text { (SD), } N=543\end{array}$ & $\begin{array}{l}\text { LSG Mean } \\
\text { (SD), } N=119\end{array}$ & $\begin{array}{l}\mathrm{MD}(95 \% \\
\mathrm{Cl})\end{array}$ & $\begin{array}{l}p- \\
\text { Value }\end{array}$ \\
\hline 20 Overall, I was highly satisfied with this CBD session. & $4.10(0.883)$ & $4.44(0.496)$ & $2.59(0.643)$ & $\begin{array}{l}1.848 \\
(1.744- \\
1.953)\end{array}$ & $\begin{array}{l}< \\
0.001\end{array}$ \\
\hline
\end{tabular}

21 Do you have any comments ?

"Dr. X was very enthusiastic during teaching. It was a very beneficial CBD".

"One of the most beneficial CBDs I took this year".

"I couldn't ask all my questions, Dr. X immediately logged off the app and didn't wait to see if we had questions"

"Was a good experience with Dr. X but she took so long around 3hours, overall she was a really good tutor"

"Dr. X was very helpful and encouraging".

"Dr. X is a good example of how a doctor should encourage her students to be strong and to study hard. She has a good method of delivering the information to the students in an easy way".

SD Standard deviation, $N$ Number of students, HSG High satisfaction group, LSG Low satisfaction group, MD Mean difference CI Confidence interval.

students rated highest mean score in the items under the category of teaching presence "students were encouraged to participate" and "faculty members' explanations were clear" with a mean score of $4.23( \pm 0.78)$, and $4.20( \pm 0.85)$ respectively. Under the technology category "During this CBD session, there were audio or visual technical issues" and "the faculty member creatively used the whiteboard, chat room, and videos" students had the lowest mean scores of $3.95( \pm 0.99)$ and $2.82( \pm 1.35)$, respectively.

Under the learning category, which was equivalent to cognitive presence, the majority of students agreed that the sessions were intellectually challenging, and that they understood the subject materials, with a mean score of $4.08( \pm 0.863)$ and $4.12( \pm 0.836)$, respectively. Moreover, under the category of group interaction and individual rapport, which reflected both teaching and social presence, the students agreed that the instructor invited them to share knowledge and had a genuine interest, with a mean score of $4.19( \pm 0.829)$ and $4.08( \pm 0.874)$, respectively.

Furthermore, $82 \%$ of the students were in the HSG versus $18 \%$ in the LSG, with a statistically significant difference in the mean scores in all categories $(p<0.001)$ except for the item "facing technical issues" $(p=0.198)$. A statistically significant difference was found in student satisfaction between the HSG and the LSG, with a mean score difference of 1.848 (95\% CI, 1.744-1.953; $p<$ 0.001). No statistically significant correlation was found between student satisfaction and technical issues $(r=$ $0.037, p=0.003$ ).

\section{Discussion}

The COVID-19 pandemic compelled the educational system to enter a new era of online learning. This study investigated the novel exposure to distance education for both students and faculty members. To the best of the authors' knowledge, this was the first study to explore student satisfaction with pediatric WVC CBD sessions' teaching quality. It provided insight into the strengths and weaknesses of student satisfaction with the teaching quality of WVC CBD sessions. Students scored the highest mean under the category of teaching presence while scored lowest under the category of technology. This indicated that students were satisfied with teaching presence despite faced challenges with technical issues, and that faculty members could improve their WVC navigation. All students had self-acess to smart devices and internet connection. Infrastructure support was provided for both students and faculty members when Blackboard platform was utilized including navigation and technical support, but not with Zoom. Of the participating students, $82 \%$ had a high satisfaction rate in all of the categories on the SEEQ questionnaire. The students' high satisfaction with the sessions' quality was not surprising considering the sessions' compatibility with the COI framework. Conrad in his literature review article explored the impact of video technology on each of the three elements of the COI framework. He points out that WVC helps with building a COI framework by establishing social presence for both the instructor and the student, engaging learners and learner-learner interactivity, increases teaching presence by allowing robust feedback and conveying of emotions to the students, and enhances cognitive presence by allowing a flipped classroom model of teaching, which encourages critical thinking and processing of information [31].

The results supported those of other studies that showed that instructor presence and an interactive teaching style were significant determinants of student satisfaction and the effectiveness of online learning environments [32, 33]. Additionally, the findings of the present study were in line with Duygu's study, which revealed a positive student perception of the teaching content, effectiveness, interaction, and idea-sharing of WVC despite experiencing technical problems related to sound quality and connection [34]. Moreover, the findings were consistent with a study by Doggett [16] that showed a positive student experience with the instructor's use of WVC technology and teaching skills despite students' 
perception that WVC technology was a barrier to interacting with the instructor. Several other studies during the COVID-19 pandemic similarly highlighted the effectiveness of WVC for delivering online teaching, engaging students, and establishing a sense of community and social presence, thereby promoting a positive student experience despite visual and audio issues [35-37].

The study found that teaching effectiveness and quality relied on teaching, cognitive, and social presence and not on technology. However, technology remains an important platform that supports teachers' educational activities. Additionally, this study illuminated the importance of satisfying the growing demands for online education while maintaining a worthwhile student learning experience.

Therefore, standards should be established for a blended-learning pediatric course that combines traditional clinical skills, face-to-face training, and innovative educational methods. Faculty development workshops and training on distance education and teaching skills and competencies should be organized, and training on navigating WVC platforms should be provided for both students and faculty members. Furthermore, set expectations should be established for the WVC netiquette system, and technical issues should be addressed by utilizing the online technical support system. Additionally, the effect of such implementations on future pediatric course quality and student and faculty satisfaction should be monitored. Finally, this study has the potential to enhance WVC teaching effectiveness and enrich online course delivery in other medical and healthcare fields.

\section{Conclusions}

WVC teaching had an overall positive outcome on student satisfaction, and teaching quality relied on teaching, cognitive, and social presence rather than technology. However, technology remains an important platform that supports teachers' educational activities. Thus, implementing a blended pediatric course to augment future course delivery is optimal.

\section{Limitations}

The study had certain limitations. First, it was conducted on one group of male students rotating in pediatrics in a single center. Therefore, inferences cannot be made about other courses or faculty members for which the education culture and environment may be different. Second, the survey responses may have been limited by inaccuracy and subjected to recall bias, since some students did not complete the survey immediately after the CBD. Third, different faculty members facilitated the CBD sessions and information on previous online course teaching was not collected. Therefore, not all students were exposed to the same orientation (such as online netiquette system and expectations) or online teaching style, skill or competency. Fourth, the study did not elaborate on student retention or success rates since the students' performance evaluations were set as pass or fail grades, and $98 \%$ of the students completed and passed the course successfully. However, this rate of completion reflected positively on the success of the teaching quality of the WVC CBD sessions.

\section{Abbreviations \\ Covid-19: Coronavirus disease 2019; LMS: Learning management system; WV: Web videoconferencing; SEEQ: Students' Evaluation of Educational Quality; CBD: Case based discussion; VC: Videoconferencing; COI: Community of inquiry framework; DPBL: Digital problem-based learning; PBL: Problem based learning}

\section{Acknowledgements}

The author would like to thank all undergraduate medical students for their feedback and cooperation during those unprecedented times. The author would also like to thank Dr. Heidi Al-wassia for the scholarly discussion which contributed to developing this article.

\section{Author's contributions}

TF wrote the initial draft and revised it. TF was the Assistant Professor responsible for collecting the student's SEEQ questionnaire responses, analyzing the data and approving the final manuscript.

\section{Funding}

Not applicable.

\section{Availability of data and materials}

The adjusted reduced SEEQ questionnaire used during the current study are available from the corresponding author on reasonable request.

Ethics approval and consent to participate

A letterhead stating the objective of the SurveyMonkey SEEQ questionnaire was sent to all participants via weblink. The study was approved by the Research Ethics Committee at King Abdulaziz University Hospital, Jeddah, Saudi Arabia. The committee's reference number is 385-20.

\section{Consent for publication}

Electronic consent to participate in this web-based online survey was obtained from the students, and participation was voluntary and anonymous.

\section{Competing interests}

The authors declare that they have no competing interests.

Received: 18 August 2020 Accepted: 15 October 2020

Published online: 31 October 2020

\section{References}

1. UNESCO. COVID-19 educational disruption and response [https://en.unesco. org/covid19/educationresponse]. Accessed 28 May 2020.

2. del Rio C, Malani PN. 2019 novel coronavirus-important information for clinicians. JAMA. 2020;323(11):1039-40.

3. Kebritchi M, Lipschuetz A, Santiague L. Issues and challenges for teaching successful online courses in higher education. J Educ Technol Syst. 2017; 46(1):4-29.

4. Philipsen B, Tondeur J, Pareja Roblin N, Vanslambrouck S, Zhu C. Improving teacher professional development for online and blended learning: a systematic meta-aggregative review. Educ Technol Res Dev. 2019;67(5): $1145-74$.

5. Bozkurt A. From distance education to open and distance learning: a holistic evaluation of history, definitions, and theories. In: Sisman-Ugur S, Eskişehir KG, editors. Handbook of research on learning in the age of transhumanism. IGI Global: Turkey; 2019. p. 252-73.

6. Moore JC. The Sloan consortium quality framework and the five pillars. The Sloan Consortium: Needham, MA; 2005. 
7. Abel R. Implementing best practices in online learning. Educ Q. 2005;28(3): 75-7.

8. Tudor Car L, Kyaw BM, Dunleavy G, Smart NA, Semwal M, Rotgans Jl, LowBeer N, Campbell J. Digital problem-based learning in health professions: systematic review and meta-analysis by the digital health education collaboration. J Med Internet Res. 2019;21(2):e12945.

9. Dziuban C, Moskal P, Thompson J, Kramer L, DeCantis G, Hermsdorfer A. Student satisfaction with online learning: is it a psychological contract? Online Learn. 2015;19(2):2.

10. Cole MT, Shelley DJ, Swartz LB. Online instruction, e-learning, and student satisfaction: a three year study. Int Rev Res Open Dist Learn. 2014;15(6):11231.

11. Bates AW. Technology, e-learning and distance education. Abingdon: Routledge; 2005.

12. Al-Samarraie H. A scoping review of videoconferencing systems in higher education. Int Rev Res Open Dist Learn. 2019;20(3):121-40.

13. Roth JJ, Pierce M, Brewer S. Performance and satisfaction of resident and distance students in videoconference courses. J Crim Justice Educ. 2020; 31(2):296-310.

14. Reese RJ, Chapman N. Promoting and evaluating evidence-based telepsychology interventions: lessons learned from the university of Kentucky telepsychology lab. In: Maheu M, Drude K, Cham WS, editors. Career paths in telemental health. Switzerland: Springer; 2016. p. 255-61.

15. Dawson S. A study of the relationship between student communication interaction and sense of community. Internet High Educ. 2006;9(3):153-62.

16. Doggett AM. The videoconferencing classroom: what do students think? J Ind Teach Educ. 2008;44(4):29-41.

17. Smith AC, White MM, McBride CA, Kimble RM, Armfield NR, Ware RS, Coulthard MG. Multi-site videoconference tutorials for medical students in Australia. ANZ J Surg. 2012;82(10):714-9.

18. Thistlethwaite JE, Davies D, Ekeocha S, Kidd JM, MacDougall C, Matthews P, Purkis J, Clay D. The effectiveness of case-based learning in health professional education. A BEME systematic review: BEME guide no. 23. Med Teach. 2012;34(6):e421-44.

19. Giesbers B, Rienties B, Tempelaar DT, Gijselaers W. Why increased social presence through web videoconferencing does not automatically lead to improved learning. E-Learn Digit Media. 2014;11(1):31-45.

20. Mader C, Ming K. Videoconferencing: A New Opportunity to Facilitate Learning. Clearing House. 2015;88(4):109-16.

21. Garrison DR, Arbaugh JB. Researching the community of inquiry framework: review, issues, and future directions. Int Higher Educ. 2007;10(3):157-72..

22. Rodgers CR, Raider-Roth MB. Presence in teaching. Teach Teach. 2006;12(3): 265-87.

23. Moore M. Theory of transactional distance. In: Keegan D, editor. Theoretical principles of distance education. New York: Routledge; 1997. p. 22-38.

24. Kanneganti A, Sia C-H, Ashokka B, Ooi SBS. Continuing medical education during a pandemic: an academic institution's experience. Postgrad Med J. 2020;96(1137):384-6.

25. Dedeilia A, Sotiropoulos MG, Hanrahan JG, Janga D, Dedeilias P, Sideris M. Medical and surgical education challenges and innovations in the COVID-19 era: a systematic review. In Vivo. 2020;34(3 suppl):1603-11.

26. Founded in 2011. Zoom is headquartered in San Jose, California, with offices around the world. Visit zoom. Com and follow @zoom_us [https:// zoom.us].

27. Marsh HW. A longitudinal perspective of students' evaluations of university teaching: ratings of the same teachers over a 13-year period. In: Annual meeting of the american educational research association, vol. 1992. San Francisco: ERIC Document ED353282; 1992. p. 1-18.

28. Corbalan M, Plaza E, Hervas E, Zaragoza E, Arcega F. Reduction of the students' evaluation of education quality questionnaire. In: Federated conference on computer science and information systems, FedCSIS, vol. 2013. Poland: Kraków; 2013. p. 713-9.

29. Grammatikopoulos V, Linardakis M, Gregoriadis A, Oikonomidis V. Assessing the students' evaluations of educational quality (SEEQ) questionnaire in Greek higher education. High Educ. 2014;70(3):395-408.

30. Coffey M, Gibbs $\mathrm{G}$. The evaluation of the student evaluation of educational quality questionnaire (SEEQ) in UK higher education. Assess Eval High Educ. 2001;26(1):89-93.

31. Conrad O. Community of Inquiry and Video in higher education: engaging students online, vol. 2015; 2015
32. Marinakou E. An investigation of factors that contribute to student satisfaction from online courses: the example of an online accounting course. In: 2013 fourth international conference on e-learning "best practices in management, design and development of e-courses: standards of excellence and creativity": 2013/05 2013; Manama. Bahrain: IEEE; 2013. p. 462-8.

33. Richardson JC, Swan K. Examining social presence in online courses in relation to students' perceived learning and satisfaction. Online Learn. 2019; 7(1):68-88.

34. Candarli D, Yuksel HG. Students' perceptions of video-conferencing in the classrooms in higher education. Procedia Soc Behav Sci. 2012:47:357-61.

35. Srinivasan DK. Medical students' perceptions and an anatomy teacher's personal experience using an e-learning platform for tutorials during the covid-19 crisis. Anat Sci Educ. 2020;13(3):318-9.

36. Almarzooq ZI, Lopes M, Kochar A. Virtual learning during the COVID-19 pandemic: a disruptive technology in graduate medical education. J Am Coll Cardiol. 2020;75(20):2635-8.

37. Gonzales-Zamora JA, Alave J, de Lima-Corvino DF, Fernandez A. Videoconferences of infectious diseases: an educational tool that transcends borders. A useful tool also for the current COVID-19 pandemic. Infez Med. 2020;28(2):135-8.

\section{Publisher's Note}

Springer Nature remains neutral with regard to jurisdictional claims in published maps and institutional affiliations.
Ready to submit your research? Choose BMC and benefit from:

- fast, convenient online submission

- thorough peer review by experienced researchers in your field

- rapid publication on acceptance

- support for research data, including large and complex data types

- gold Open Access which fosters wider collaboration and increased citations

- maximum visibility for your research: over $100 \mathrm{M}$ website views per year

At BMC, research is always in progress.

Learn more biomedcentral.com/submissions 